\title{
Sensitivity Analysis of the Estimation of the Single-Number Sound Absorption Evaluation Index $D L_{\alpha}$
}

\author{
Wojciech BATKO, Paweł PAWLIK, Grażyna WSZOŁEK
}

AGH University of Science and Technology

Faculty of Mechanical Engineering and Robotics, Department of Mechanics and Vibroacoustics al. A. Mickiewicza 30, 30-059 Kraków, Poland; e-mail: \{batko, pawlik, grazyna.wszolek\}@agh.edu.pl

(received April 1, 2016; accepted May 15, 2017)

\begin{abstract}
Acoustic barriers are assigned to the respective categories of sound absorbing properties on the basis of a single-number sound absorption evaluation index. Categories of absorbing properties play a significant role in selecting the barrier type for the given localisation. The estimation of the single-number sound absorption evaluation index is performed, among others, by means of measuring the sound absorption coefficient of the analysed acoustic barrier sample in the reverberation chamber.

The sensitivity analysis of the determination of the single-number sound absorption evaluation index was performed in this work. The estimation of the input parameters uncertainty contribution to the expanded uncertainty of the sound absorption evaluation index, was done first. The Monte Carlo method and the reduction interval arithmetic were used for this aim.

The relative sensitivity coefficients were determined by means of the author's method based on the interval arithmetic. These coefficients contain information concerning the quantitative influence of the given input value on the final result.
\end{abstract}

Keywords: sensitivity analysis, acoustic barriers, interval arithmetic, Monte Carlo method.

\section{Introduction}

The single-number sound absorption evaluation index $D L_{\alpha}$ is estimated for the needs of determining the respective category of absorption properties of flat acoustic barriers. This classification is important in decisive processes concerning the application of the given kind of acoustic barrier in the specific localisation. Therefore the uncertainty of estimating individual input parameters - needed for the determination of index $D L_{\alpha}$ - should be as small as possible and very accurately determined.

The hereby paper presents the analysis of contributions of individual input parameters into the determination uncertainty of the sound absorption evaluation index. Such approach is aimed at emphasizing the importance of certain parameters in determining the analysed index. The Monte Carlo method was applied for the uncertainty contribution estimation. This method was used to perform the propagation of the distribution of input parameters generated on the bases of measurement data. The same analysis was simultaneously performed with using the reduction interval arithmetic, which was previously applied for the uncertainty estimation in paper (BATKO, PAWLIK, 2012). Other, not classic methods of the uncertainty estimation can be found in papers (STĘPIEŃ, 2016; PRZYSUCHA et al., 2015).

In addition, the author's method of determining the relative sensitivity coefficients based on interval analysis, is presented in this paper. This methods allows to determine experimentally the quantitative influence of the input values uncertainty on the uncertainty of the result.

\section{Single-number sound absorption evaluation index $D L_{\alpha}$}

A single-number index of the sound absorption evaluation $D L_{\alpha}$, defined in the standard (PN-EN 17931:2013-05), is described by the equation:

$$
D L_{\alpha}=-10 \log _{10}\left|1-\frac{\sum_{i=1}^{18} \alpha_{s i} 10^{0.1 L_{i}}}{\sum_{i=1}^{18} 10^{0.1 L_{i}}}\right|,
$$


where $L_{i}$ - normalised sound A level, in decibels, of the road traffic noise in the $i$-th $1 / 3$-octave frequency band, defined acc. to standard (PN-EN 1793-3:2001), $\alpha_{s i}-$ sound absorption coefficient in the $i$-th $1 / 3$-octave frequency band, is calculated acc. to the dependence (2) contained in (PN-EN ISO 354:2005),

$$
\alpha_{S}=\frac{V}{S}\left[55.3\left(\frac{1}{c_{2} T_{2}}-\frac{1}{c_{1} T_{1}}\right)-4\left(m_{2}-m_{1}\right)\right]
$$

where $V$ - volume of the reverberation chamber $\left[\mathrm{m}^{3}\right]$, $S$ - surface area of the tested sample $\left[\mathrm{m}^{2}\right], T_{1}, T_{2}-$ reverberation time measured in the empty reverberation chamber and in the chamber with the sample [s], $c_{1}, c_{2}$ - sound propagation velocity in the empty reverberation chamber and in the chamber with the sample $[\mathrm{m} / \mathrm{s}]$, dependent on the air temperature, $m_{1}$, $m_{2}$ - power damping coefficient for climatic conditions, which occur in the empty reverberation chamber and in the chamber with the sample $[1 / \mathrm{m}]$, calculated in accordance with (ISO 9613-1), dependent, among others, on the atmospheric pressure, humidity and air temperature.

On the basis of the single-number index of the sound absorption evaluation the category of the absorptive performance of the tested acoustic barrier is determined. Classification of the single-number sound absorption evaluation index is done on the basis of Table 1 contained in the standard (PN-EN 1793-1: 2013-05).

Table 1. Categories of absorptive performance.

\begin{tabular}{|c|c|}
\hline Category & $D L_{\alpha}[\mathrm{dB}]$ \\
\hline $\mathrm{A} 0$ & Not determined \\
\hline $\mathrm{A} 1$ & $<4$ \\
\hline $\mathrm{A} 2$ & 4 to 7 \\
\hline $\mathrm{A} 3$ & 8 to 11 \\
\hline $\mathrm{A} 4$ & 12 to 15 \\
\hline A5 & $>15$ \\
\hline
\end{tabular}

The method and accuracy of determining individual parameters needed for the index $D L_{\alpha}$ determination can have a significant influence on assigning the tested barrier into the relevant category of absorbing properties (WSZOŁEK, 2014). The influence of the uncertainty measurements of sample surface $S$, reverberation times $T_{1}$ and $T_{2}$ as well as conditions in the anechoic room (temperature, pressure, humidity), on which the power damping coefficients $m_{1}$ and $m_{2}$ depend, was also presented in this paper.

\section{Analytical methods of determining contribution of expanded uncertainty}

Sensitivity of individual parameters to the uncertainty of determining the single-number sound absorp- tion evaluation index, was performed by experimental method. This method is based on introducing the uncertainty of individual parameters - at maintaining the remaining input parameters constant - and on testing the output uncertainty changes in dependence on the input uncertainty changes.

The note concerning the way of uncertainty assessment, which should be done according to the Guide to the expression of uncertainty in measurement (ISO/IEC Guide 98-3:2008), is written in Appendix $\mathrm{C}$ of the standard concerning evaluations of sound absorbing properties of the designed road equipment (PN-EN 1793-1:2013-05). In the supplement 1 of this standard (ISO/IEC Guide 98-3-SP1:2008) the application of the Monte Carlo method for the uncertainty assessment is suggested in situations when:

- uncertainties are of significantly different values;

- partial derivatives are difficult for calculating;

- distribution of output values is neither Gaussian nor t-Student;

- estimate of output value is comparable with its standard uncertainty;

- mathematical model of the measured value is arbitrarily complicated;

- distributions of input values are asymmetrical.

Very often, it is difficult to assign reliably to the above assumptions in modelling the acoustic parameters. The index of the sound absorption estimation is presented as decibel numbers, what in case of relatively large uncertainty values leads to asymmetric distribution of this parameter probability. On account of this, the application of the uncertainty propagation law can provide erroneous conclusions.

To this end, the Monte Carlo method was applied to the sensibility testing of the single number sound absorption index. The method of the sensitivity estimation by means of the interval arithmetic method and the comparison of results obtained by both methods was also presented in this paper.

\subsection{Monte Carlo method}

In the document (ISO/IEC Guide 98-3-SP1:2008) the rule of propagation of probability distributions realised by using the Monte Carlo method was elaborated. The following course of proceedings was undertaken at applying the Monte Carlo method:

1) The analysed parameter data collection of the given probability distribution was generated. For the reverberation time the t-Student distribution was applied, while for the uncertainty assessment of the sample sensitivity measurements the uniform distribution was applied.

2) $10^{6}$ tests were generated and the draw was performed without returning the input parameter to the data collection, at the remaining parameters being constant. 
3) Output values for each test were calculated on the basis of the model of the single-number sound adsorption evaluation index.

4) Output values were sorted, according to not diminishing order, to determine the approximate distribution function of the output value.

5) The confidence interval for confidence level 1 $\alpha=0.95$ was determined from the distribution function of the output value.

\subsection{Interval arithmetic}

The sensitivity analysis was also performed by using the interval arithmetic expansion, such as the reduction interval arithmetic. Operations on intervals had their beginning already in the 50 -s, in the works of the Polish mathematician Mieczysław Warmus. The concept of calculations based on interval numbers, applied for determining the round-off errors, was described in the work (WARMUS, 1956). In the 60-s, operations on intervals were defined as the interval arithmetic by Moore, in his Ph.D. dissertation (Moore, 1962) and book (Moore, 1966). The interval arithmetic was the widely applied method, however in several cases it was leading to overestimation of the result interval. On account of this, several expansions of this arithmetic were developed. One of them is the reduction interval arithmetic, proposed by JAKUBIEC (2002). In the reduction interval arithmetic the interval is written by means of the middle, $\operatorname{mid}(x)$, and radius, $\operatorname{rad}(x)$ :

$$
\breve{x}=\operatorname{mid}(x)=\frac{\underline{x}+\bar{x}}{2}, \quad \operatorname{rad}(x)=\frac{|\bar{x}-\underline{x}|}{2},
$$

where $\underline{x}$ is the interval lower limit - infimum, while $\bar{x}$ the upper limit - supremum.

Connections occurring between intervals in the classic and reduction interval arithmetic are the same. However, the basic advantage of the reduction interval arithmetic is the introduction of the coherence coefficient, which describes properties of intervals as well as the correlation between intervals, which brings about the reduction of the interval width.

The interval - in a sense of the interval arithmetic - can be treated as a sum of its two independent components: middle $\breve{x}$ and unloaded interval $\pm \operatorname{rad}(x)$ :

$$
\begin{aligned}
x & =[\underline{x}, \bar{x}]=[\breve{x}-\operatorname{rad}(x), \breve{x}+\operatorname{rad}(x)] \\
& =\breve{x} \pm \operatorname{rad}(x)=\breve{x}+[-\operatorname{rad}(x), \operatorname{rad}(x)] .
\end{aligned}
$$

Due to this approach, operations on intervals can be performed independently for these two components. Operations on intervals middles, which are real numbers, are performed according to rules binding for these numbers, while operations on unloaded intervals are done by means of the reduction interval arithmetic. In the reduction interval arithmetic, for each pair of intervals the number $r_{i j}$, called the coherence coefficient, is determined:

$$
r_{\mathrm{ij}} \in R,-1<r_{\mathrm{ij}}<1 .
$$

This coefficient describes properties of individual intervals and dependencies between the given pair of intervals, which means that it is dependent on the correlation between intervals and on the density probability distribution function of the parameters collection. It should be emphasised, that incorrect determination of this coefficient can lead to overestimation of the result interval.

The basic mathematical operations for the reduction arithmetic are presented below.

- Addition of interval numbers:

where

$$
y=x_{1}+x_{2}=\breve{y}+[-\operatorname{rad}(y),+\operatorname{rad}(y)],
$$

$$
\begin{aligned}
& \operatorname{mid}(y)=\operatorname{mid}\left(x_{1}\right)+\operatorname{mid}\left(x_{2}\right) \\
& \operatorname{rad}(y)=\sqrt{a^{*}}
\end{aligned}
$$

where

$$
a^{*}=\operatorname{rad}^{2}\left(x_{1}\right)+\operatorname{rad}^{2}\left(x_{2}\right)+2 \operatorname{rad}\left(x_{1}\right) \operatorname{rad}\left(x_{2}\right) r_{12} .
$$

- Subtraction of interval numbers:

$$
y=x_{1}-x_{2}=\breve{y}+[-\operatorname{rad}(y),+\operatorname{rad}(y)],
$$

where

$$
\begin{aligned}
& \operatorname{mid}(y)=\operatorname{mid}\left(x_{1}\right)-\operatorname{mid}\left(x_{2}\right) \\
& \operatorname{rad}(y)=\sqrt{b^{*}}
\end{aligned}
$$

where

$$
b^{*}=\operatorname{rad}^{2}\left(x_{1}\right)+\operatorname{rad}^{2}\left(x_{2}\right)-2 \operatorname{rad}\left(x_{1}\right) \operatorname{rad}\left(x_{2}\right) r_{12} .
$$

- Multiplication of interval numbers:

$$
y=x_{1} \cdot x_{2}=\breve{y}+[-\operatorname{rad}(y),+\operatorname{rad}(y)],
$$

where

$$
\begin{aligned}
& \operatorname{mid}(y)=\operatorname{mid}\left(x_{1}\right) \cdot \operatorname{mid}\left(x_{2}\right), \\
& \operatorname{rad}(y)=\sqrt{c^{*}}
\end{aligned}
$$

where

$$
\begin{aligned}
c^{*}= & \breve{x}_{2}^{2} \operatorname{rad}^{2}\left(x_{1}\right)+\breve{x}_{1}^{2} \operatorname{rad}^{2}\left(x_{2}\right) \\
& -2 \breve{x}_{1} \breve{x}_{2} \operatorname{rad}\left(x_{1}\right) \operatorname{rad}\left(x_{2}\right) r_{12} .
\end{aligned}
$$

Utilising the described above formalism, the analysis of the contribution of the uncertainty of individual input values to the uncertainty of the singlenumber sound absorption evaluation index, was performed. The parameter, which contribution was investigated, was written in the interval number form of a radius equal to the expanded uncertainty, at the remaining parameters being constant and represented as interval numbers of radiuses equal 0. Expanded uncertainties for input values were evaluated with the confidence level of 0.95 . Due to such approach the interval number of the index $D L_{\alpha}$, which radius is equal to the expanded uncertainty of this parameter, was achieved. 


\section{Interval method of determining relative sensitivity coefficients}

The relative sensitivity analysis was also performed in this work. It consists in determining the relative sensitivity coefficients for individual parameters. These coefficients provide information on the quantitative influence of the given input value on the obtained result. For example: when the relative sensitivity coefficient equals 3 and if the given variable changes its value by $1 \%$, the result will change by $3 \%$.

The model sensitivity analysis is used for investigating, in which degree individual input parameters influence the modelling result. In order to determine the dependence of the modelling result on individual input parameters, partial derivatives of the model function should be evaluated. These derivatives are called the sensitivity coefficients. For the function: $y=f\left(x_{1}, x_{2}, \ldots, x_{N}\right)$, where $N$ is the input parameters number, the sensitivity coefficients can be evaluated as follows:

$$
c_{i}=\frac{\partial y}{\partial x_{i}}, \quad i=1,2,3, \ldots, N .
$$

Determinations of these coefficients for complex functions becomes problematic, especially in numerical applications. Instead of calculating sensitivity coefficients from the function, they can be determined experimentally. It can be done by: measuring the change of parameter $y$ caused by the individual change of the selected input value $x_{i}$, when the remaining input values remain constant (ISO/IEC Guide 98-3: 2008).

The author's solution of determining the empirical sensitivity coefficients with the application of the interval arithmetic, was proposed in the hereby paper. Such solution allows to evaluate these coefficients at expanding the function by higher order terms of the Taylor series, without the necessity of symbolic determining partial derivatives of a higher order. On the other hand, the accuracy of this function value evaluation related to the omission of free terms - is taken into account in the interval number. For monotonic functions the values at the endpoints of the variability interval are calculated, while for not monotonic functions the extremes occurring in the considered interval. Such approach allows for more accurate determining the influence of the input parameters uncertainty on the output parameter uncertainty (BATKO et al., 2015).

The standard uncertainty of parameter $y$, caused solely by the standard uncertainty of the input parameter $x_{i}$, can be written as follows:

$$
u_{i}(y)=\frac{\partial y}{\partial x_{i}} u\left(x_{i}\right),
$$

where $u_{i}(y)$ - standard uncertainty of the output parameter $y$ caused by the uncertainty of $x_{i}, u\left(x_{i}\right)-$ standard uncertainty of the input parameter $x_{i}, \frac{\partial y}{\partial x_{i}}-$ sensitivity coefficient - partial derivative of function $y$ from parameter $x_{i}$.

Equation (16) can be rearranged in a following way:

$$
\frac{\partial y}{\partial x_{i}}=\frac{u_{i}(y)}{u\left(x_{i}\right)}=c_{i}
$$

Quotient $\frac{u_{i}(y)}{u\left(x_{i}\right)}$ can be determined by means of the interval arithmetic formalism, taking uncertainty $u\left(x_{i}\right)$ as the input interval radius $\operatorname{rad}\left(x_{i}\right)$, while $u_{i}(y)$ as the radius $\operatorname{rad}(y)$ of the interval number $\mathbf{y}$ (Eq. (19)), determined by means of the interval analysis of function $y=f\left(x_{i}\right)$ (in accordance with the interval arithmetic formalism). Then Eq. (17) will be:

$$
\begin{aligned}
\frac{\partial y}{\partial x_{i}} & =\frac{u_{i}(y)}{u\left(x_{i}\right)}=\frac{\operatorname{rad}(y)}{\operatorname{rad}\left(x_{i}\right)}=c_{i}, \\
\mathbf{y} & =\breve{y}+[-\operatorname{rad}(y)+\operatorname{rad}(y)] .
\end{aligned}
$$

Utilising the interval arithmetic formalism, interval y (19) should be determined at the assumed $\operatorname{rad}\left(x_{i}\right)$ uncertainty of the parameter - for which the sensitivity coefficient is to be determined - and at zero values of interval radiuses of the remaining input parameters.

In a similar fashion the relative sensitivity coefficients can be calculated:

$$
W_{i}=\frac{x_{i}}{y} \frac{\partial y}{\partial x_{i}} .
$$

Using equation (18) equation (20) can be written as follows:

$$
W_{i}=\frac{x_{i}}{y} \frac{\partial y}{\partial x_{i}}=\frac{x_{i}}{y} \frac{\operatorname{rad}(y)}{\operatorname{rad}\left(x_{i}\right)}
$$

\section{Results of the performed investigations}

Three samples of barriers were analysed: samples No. 1 and 2 - of the 'green wall' type (Fig. 1) and sample No. 3 made of aluminium (Fig. 2).

Sample No. 1 'green wall' consisted of the following layers:

- grate with ribbed steel bars $(\phi=8 \mathrm{~mm})$ with mesh size $200 \times 200 \mathrm{~mm}$,

- polyethylene mesh with mesh size $7 \times 7 \mathrm{~mm}$, thickness $-3 \mathrm{~mm}$,

- mineral wool board with fizelin, density $80 \mathrm{~kg} / \mathrm{m}^{3}$, thickness - $50 \mathrm{~mm}$,

- insulation board, density $1950 \mathrm{~kg} / \mathrm{m}^{3}$, thickness $8 \mathrm{~mm}$,

- mineral wool board with fizelin, density $80 \mathrm{~kg} / \mathrm{m}^{3}$, thickness - $50 \mathrm{~mm}$,

- polyethylene mesh with mesh size $7 \times 7 \mathrm{~mm}$, thickness $-3 \mathrm{~mm}$,

- grate with ribbed steel bars $(\phi=8 \mathrm{~mm})$ with mesh size $200 \times 200 \mathrm{~mm}$. 


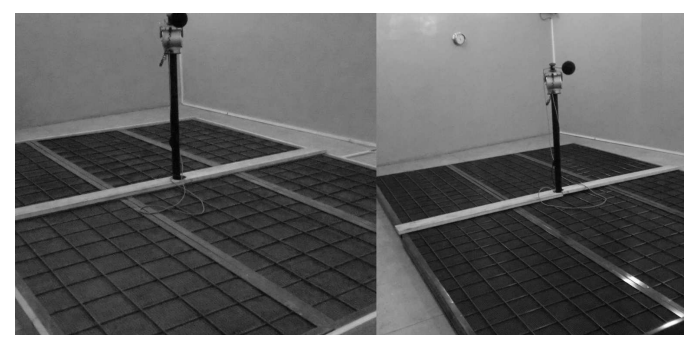

Fig. 1. Samples No. 1 and 2 of barriers of the 'green wall' type.

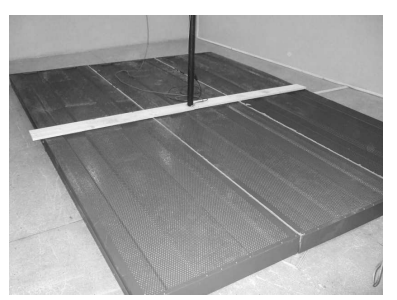

Fig. 2. Sample No. 3 of sound-absorbing panels of aluminium sheet perforated and profiled.

Sample No. 2 'green wall' consisted of the following layers:

- grate with ribbed steel bars $(\phi=6 \mathrm{~mm})$ with mesh size $150 \times 150 \mathrm{~mm}$,

- polyethylene mesh with mesh size $7 \times 7 \mathrm{~mm}$,

- glass fiber mesh with mesh size $5 \times 5 \mathrm{~mm}$,

- mineral wool board, density $110 \mathrm{~kg} / \mathrm{m}^{3}$, thickness $-60 \mathrm{~mm}$,

Table 2. Mean values and experimental standard deviation of the mean of reverberation time for empty chamber T1 and the chamber with the sample T2.

\begin{tabular}{|c|c|c|c|c|c|c|c|c|c|c|c|c|}
\hline \multirow{2}{*}{$\begin{array}{c}\text { Center frequency } \\
\text { of } 1 / 3 \text { octave band } \\
{[\mathrm{Hz}]}\end{array}$} & \multicolumn{4}{|c|}{ Sample No. 1 'green wall' } & \multicolumn{4}{|c|}{ Sample No. 2 'green wall' } & \multicolumn{4}{|c|}{$\begin{array}{c}\text { Sample No. } 3 \text { sound-absorbing } \\
\text { panels of aluminium sheet } \\
\text { perforated and profiled }\end{array}$} \\
\hline & $T_{1}[\mathrm{~s}]$ & $u\left(T_{1}\right)[\mathrm{s}]$ & $T_{2}[\mathrm{~s}]$ & $u\left(T_{2}\right)[\mathrm{s}]$ & $T_{1}[\mathrm{~s}]$ & $u\left(T_{1}\right)[\mathrm{s}]$ & $T_{2}[\mathrm{~s}]$ & $u\left(T_{2}\right)[\mathrm{s}]$ & $T_{1}[\mathrm{~s}]$ & $u\left(T_{1}\right)[\mathrm{s}]$ & $T_{2}[\mathrm{~s}]$ & $u\left(T_{2}\right)[\mathrm{s}]$ \\
\hline 100 & 6.42 & 0.11 & 2.14 & 0.06 & 6.98 & 0.10 & 1.89 & 0.07 & 6.63 & 0.18 & 1.58 & 0.04 \\
\hline 125 & 6.37 & 0.13 & 2.55 & 0.04 & 7.02 & 0.15 & 2.36 & 0.04 & 6.43 & 0.25 & 2.15 & 0.05 \\
\hline 160 & 5.07 & 0.10 & 1.92 & 0.03 & 5.10 & 0.15 & 1.63 & 0.05 & 5.39 & 0.13 & 1.71 & 0.04 \\
\hline 200 & 5.14 & 0.07 & 1.99 & 0.05 & 5.28 & 0.10 & 1.59 & 0.04 & 5.07 & 0.05 & 1.92 & 0.05 \\
\hline 250 & 6.21 & 0.06 & 2.17 & 0.04 & 6.57 & 0.09 & 1.84 & 0.05 & 6.21 & 0.08 & 2.04 & 0.04 \\
\hline 315 & 6.79 & 0.07 & 2.09 & 0.03 & 7.05 & 0.05 & 1.85 & 0.03 & 6.79 & 0.08 & 1.97 & 0.03 \\
\hline 400 & 6.94 & 0.05 & 1.88 & 0.03 & 7.14 & 0.06 & 1.68 & 0.04 & 6.85 & 0.05 & 1.77 & 0.02 \\
\hline 500 & 6.86 & 0.03 & 1.77 & 0.03 & 7.05 & 0.04 & 1.69 & 0.02 & 6.89 & 0.06 & 1.65 & 0.02 \\
\hline 630 & 6.54 & 0.04 & 1.77 & 0.03 & 6.66 & 0.05 & 1.71 & 0.02 & 6.61 & 0.05 & 1.64 & 0.02 \\
\hline 800 & 6.17 & 0.03 & 1.75 & 0.02 & 6.19 & 0.04 & 1.76 & 0.02 & 6.28 & 0.04 & 1.70 & 0.02 \\
\hline 1000 & 5.77 & 0.04 & 1.80 & 0.02 & 5.85 & 0.03 & 1.75 & 0.01 & 5.85 & 0.03 & 1.73 & 0.02 \\
\hline 1250 & 5.27 & 0.03 & 1.80 & 0.01 & 5.48 & 0.02 & 1.79 & 0.01 & 5.39 & 0.04 & 1.73 & 0.02 \\
\hline 1600 & 4.72 & 0.03 & 1.73 & 0.02 & 5.16 & 0.03 & 1.81 & 0.01 & 4.92 & 0.03 & 1.77 & 0.01 \\
\hline 2000 & 4.18 & 0.03 & 1.66 & 0.01 & 4.81 & 0.02 & 1.79 & 0.02 & 4.37 & 0.03 & 1.73 & 0.01 \\
\hline 2500 & 3.60 & 0.02 & 1.60 & 0.01 & 4.47 & 0.02 & 1.78 & 0.01 & 3.82 & 0.03 & 1.66 & 0.01 \\
\hline 3150 & 2.94 & 0.01 & 1.47 & 0.01 & 3.99 & 0.02 & 1.75 & 0.01 & 3.11 & 0.02 & 1.57 & 0.01 \\
\hline 4000 & 2.31 & 0.01 & 1.29 & 0.01 & 3.44 & 0.01 & 1.64 & 0.01 & 2.49 & 0.01 & 1.42 & 0.01 \\
\hline 5000 & 1.66 & 0.01 & 1.07 & 0.01 & 2.80 & 0.01 & 1.48 & 0.01 & 1.81 & 0.01 & 1.23 & 0.01 \\
\hline
\end{tabular}

- concrete slab, density $2000 \mathrm{~kg} / \mathrm{m}^{3}$, thickness -

- mineral wool board, density $110 \mathrm{~kg} / \mathrm{m}^{3}$, thickness $-40 \mathrm{~mm}$,

- glass fiber mesh with mesh size $5 \times 5 \mathrm{~mm}$,

- polyethylene mesh with mesh size $7 \times 7 \mathrm{~mm}$,

- grate with ribbed steel bars $(\phi=6 \mathrm{~mm})$ with mesh size $150 \times 150 \mathrm{~mm}$.

Sample No. 3 of sound-absorbing panels of aluminium sheet perforated and profiled consisted of the following layers:

- aluminium sheet perforated and profiled (about $26 \%$ perforation), thickness $-1 \mathrm{~mm}$,

- mineral wool board, density $80 \mathrm{~kg} / \mathrm{m}^{3}$, thickness $-50 \mathrm{~mm}$,

- insulation board, density $1950 \mathrm{~kg} / \mathrm{m}^{3}$, thickness $8 \mathrm{~mm}$,

- air gap, thickness - $50 \mathrm{~mm}$,

- aluminium sheet with trapezoidal profile, thickness $-1 \mathrm{~mm}$.

For each sample the reverberation time was measured in 18 measuring points in the chamber with and without samples. Then average values and standard deviations of the mean of the measured reverberation times $T_{1}$ and $T_{2}$ for each $1 / 3$ octave band were evaluated (Table 2). $6 \mathrm{~mm}$, 
The determined average values and standard deviations were used for the generation of the probability distributions of the measured reverberation times. The t-Student distribution of $n-1$ degrees of freedom, where $n$ is the number of performed measurements for each $1 / 3$ octave band (in this case $n=18$ ), was assumed.

\subsection{Analysis of the uncertainty contribution of input parameters to the complex expanded uncertainty}

First of all the contribution of the uncertainty of the reverberation time $T_{1}$ and $T_{2}$ measurements to the expanded uncertainty (for the confidence level 0.95) of the sound absorption index $D L_{\alpha}$, was investigated. The histogram of the index $D L_{\alpha}$ values determined by means of the Monte Carlo method together with the determined values of the right and left-sided uncertainty, caused solely by the uncertainty of parameters $T_{1}$ and $T_{2}$, is shown in Fig. 3. It can be observed that the left and right-sided uncertainties are different, which testifies on the asymmetry of the obtained probability distribution. On account of the fact that the right-sided uncertainty in the tested uncertainty distribution is higher than the left-handed, the rightsided uncertainty is analysed in further sections of this paper.

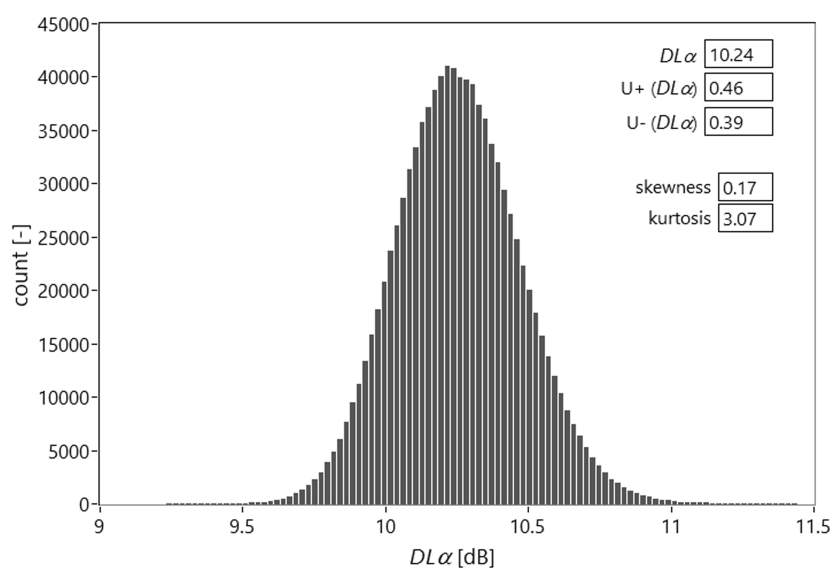

Fig. 3. Histogram of the index $D L_{\alpha}$ value determined by the Monte Carlo method together with determined values of the right and left-sided uncertainty - sample No. 1 'green wall' type.

Next, the contribution of the reverberation time uncertainty in $1 / 3$ octave bands on the uncertainty of the $D L_{\alpha}$ index determination was investigated. The contribution of the reverberation time uncertainty measured in the reverberation chamber without the sample was presented in Fig. 4 (black), while with the sample No. 1 ('green wall' type) in Fig. 4 (grey). For this aim the Monte Carlo method as well as the Reduction Interval Arithmetic were used and the obtained results were not differing by more than $0.001 \mathrm{~dB}$. The Fig. 4 shows a significantly larger con-

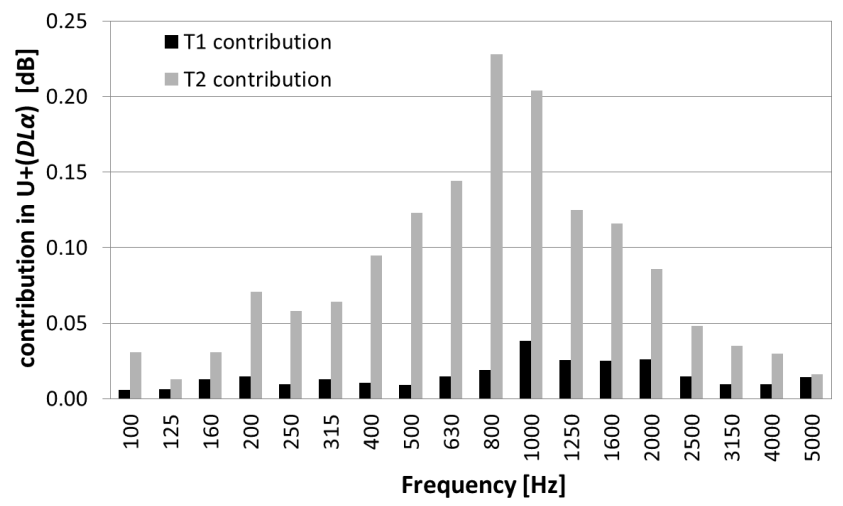

Fig. 4. Contribution of the reverberation time $T_{1}$ and $T_{2}$ uncertainty to the expanded uncertainty of the $D L_{\alpha}$ index - for empty chamber (black) and the chamber with the sample No. 1 'green wall' type (grey).

tribution to the expanded uncertainty of the $D L_{\alpha}$ index for the reverberation time uncertainty for chamber with the sample.

Then the influence of the uncertainty of the surface area measurement on the uncertainty of the singlenumber sound absorption evaluation index, was investigated. Methods described in the Sec. 3 of this paper were applied. The described procedures were performed successively for various values of the uncertainty of the sample length and width measurements (0.01 $\mathrm{m}$ to $0.05 \mathrm{~m})$.

The maximum uncertainty value, $0.05 \mathrm{~m}$ was assumed on the basis of the experience in the $D L_{a}$ index investigations carried out in the Department of Mechanics and Vibroacoustics, AGH. Figure 5 presents
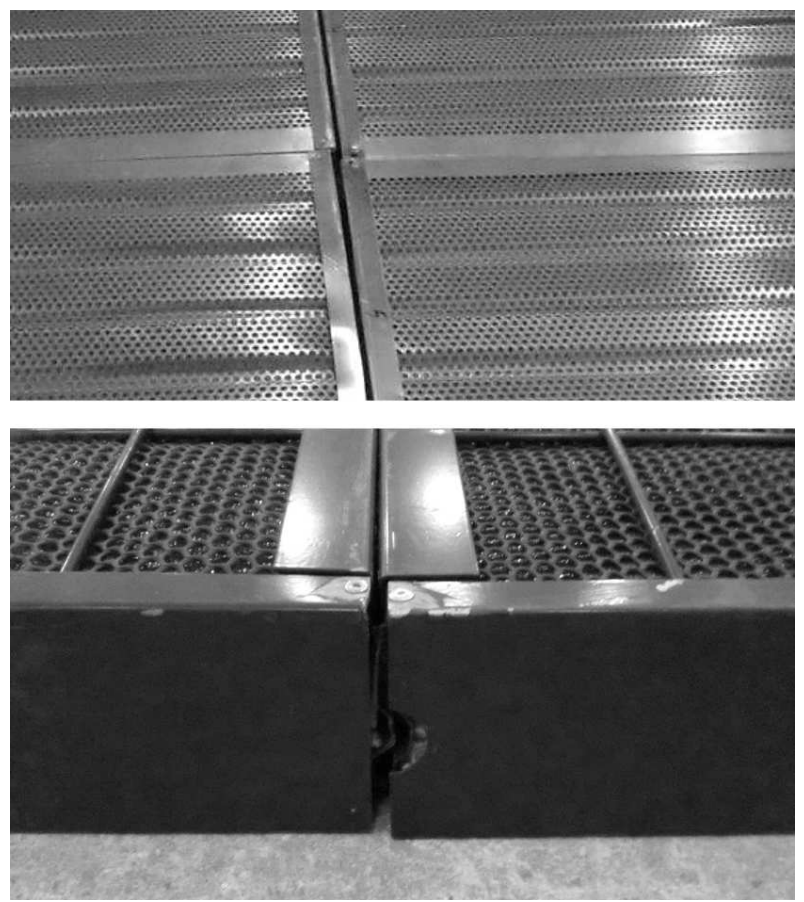

Fig. 5. Imperfections in making the samples supplied by their producers. 
imperfections of test samples supplied by producers, which make impossible to measure accurately the sample dimensions.

Also the contribution of the uncertainty of measurements of the sample length and width to the expanded uncertainty of the $D L_{\alpha}$ was investigated. The histogram of the results obtained by the Monte Carlo method were shown in Fig. 6.

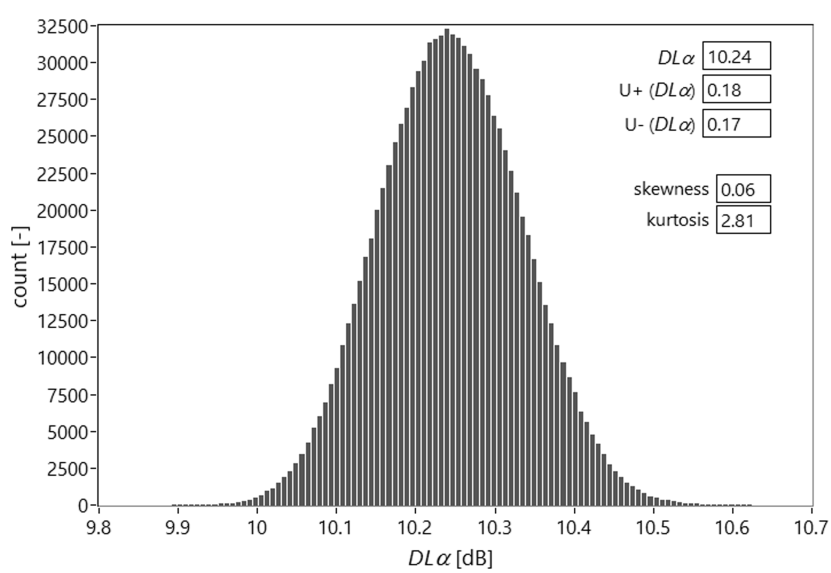

Fig. 6. Histogram of the values generated by the Monte Carlo method for the expanded uncertainty $U(a)=U(b)=$ $0.05 \mathrm{~m}$, at constant values of the remaining input parameters - sample No. 1, 'green wall' type.

The dependence of the $D L \alpha$ index uncertainty on the measuring uncertainty of the tested sample length, was also investigated (Fig. 7).

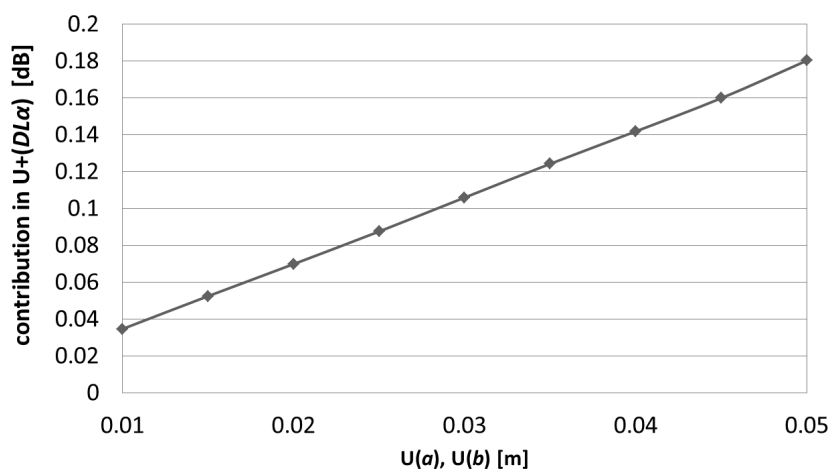

Fig. 7. Dependence of the $D L_{\alpha}$ index uncertainty on the measuring uncertainty of the tested sample length.

\subsection{Relative sensitivity coefficients}

Utilising the method described in Sec. 4 the relative sensitivity coefficients were determined for all input parameters, needed for the determination of the sound absorption evaluation index $D L_{\alpha}$. The list of values of the relative sensitivity coefficients of individual input parameters, for the sample No. 1 and 2 ('green wall' type) and No. 3 (sound-absorbing panels of aluminium sheet perforated and profiled), is given in Figs. 8, 9 and 10 .

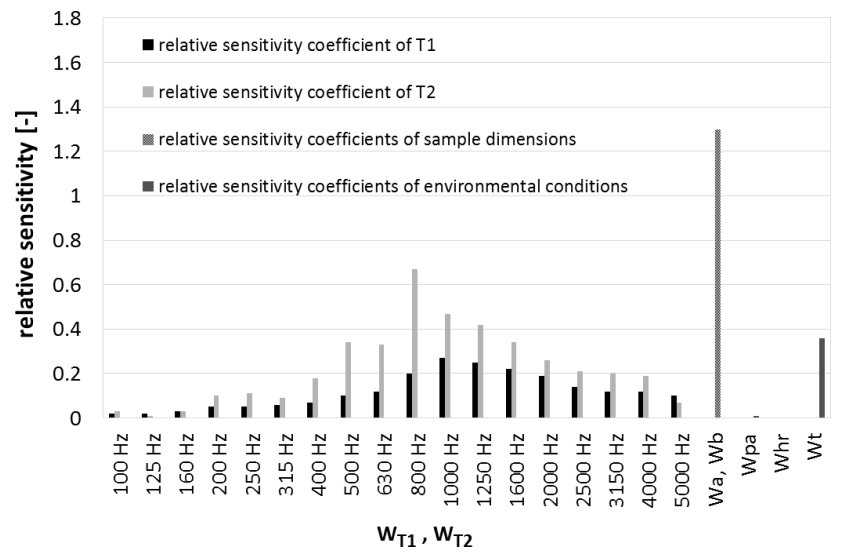

Fig. 8. List of values of the relative sensitivity coefficients of individual input parameters - sample No. 1, 'green wall' type.

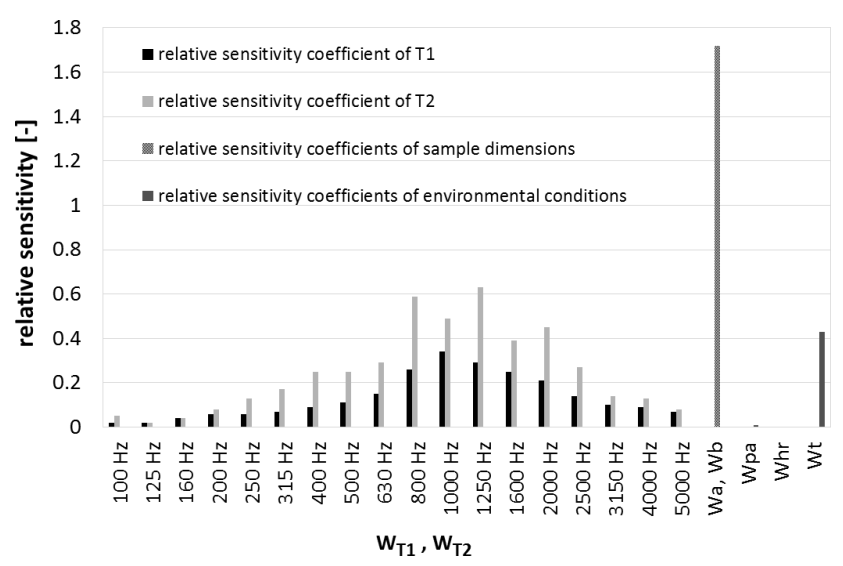

Fig. 9. List of values of the relative sensitivity coefficients of individual input parameters - sample No. 2, 'green wall' type.

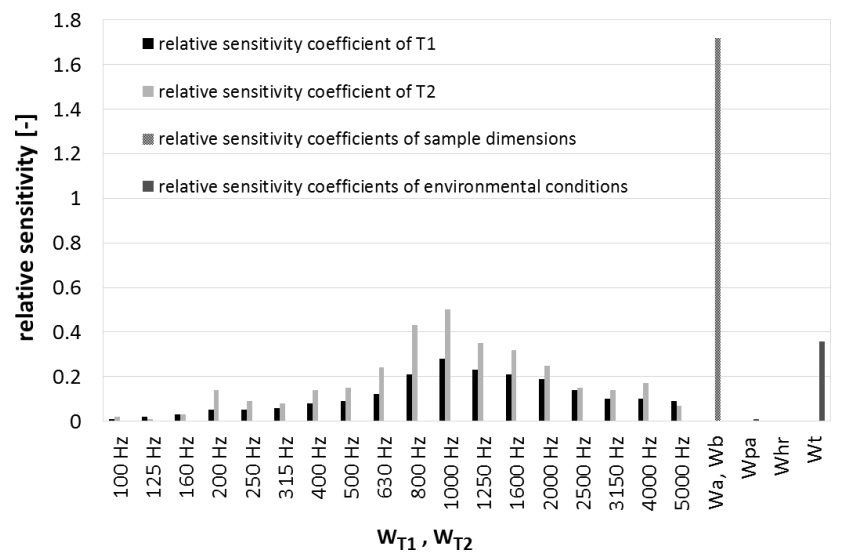

Fig. 10. List of values of the relative sensitivity coefficients of individual input parameters - sample No. 3, soundabsorbing panels of aluminium sheet perforated and profiled.

A significant influence of the uncertainty of the single-number sound absorption evaluation $D L_{\alpha}$ index on uncertainties of the tested sample measured dimensions can be observed in all analysed samples. The uncertainty of the evaluation of the sound absorption co- 
efficient in some $1 / 3$ octave bands is also significant. Relative values of the sensitivity coefficient for the ambient temperature in the reverberation chamber are also worth noticing. The values of relative sensitivity coefficients for values for individual parameters depend on the sample, however, a certain tendency can be observed in the obtained results.

\section{Conclusions}

The paper presents the analysis of the sensitivity of the single-number sound absorption evaluation in$\operatorname{dex}, D L_{\alpha}$. This type of analysis allowed to select the input parameters, which uncertainties had a significant influence on the final uncertainty. It should be noted that the final uncertainty value depends on the model and also on the values of the input parameters, and it is not possible to uniquely determine the universal values for all types of screens.

Two approaches to the evaluation of the contribution of uncertainties of individual parameters to the uncertainty of $D L_{\alpha}$ were presented in the hereby paper. One approach is based on the propagation of the distribution by the Monte Carlo method, while the second on the reduction interval arithmetic. The main advantage of these two methods is the lack of assumption concerning distributions of input and output values. However, the Monte Carlo method requires a high calculation power and, in consequence, the calculations are time consuming. On the other hand, at the application of the reduction interval arithmetic, precautions should be taken at selecting the coefficient $r$, since its erroneous determination can lead to overestimations of the output parameters intervals. The results obtained by both methods of evaluation of uncertainty contribution did not differ by more than $0.001 \mathrm{~dB}$, which in acoustic applications - is satisfactory.

The author's method based on reduction interval arithmetic was applied for determining the relative sensitivity coefficients. This method allowed to determine the influence of the uncertainty of measuring the sample $S$ area and reverberation time $T_{1}$ and $T_{2}$ as well as the influence of the uncertainty of conditions in the anechoic chamber (temperature, pressure and humidity), on the uncertainty of determining the singlenumber sound absorption evaluation index $D L_{\alpha}$.

\section{Acknowledgment}

Investigations were financed from the statute resources of the Department of Mechanics and Vibroacoustics of AGH University of Science and Technology (project No. 11.11.130.955).

\section{References}

1. Batko W., Pawlik P. (2012), New Approach to the Uncertainty Assessment of Acoustic Effects in the Environment, Archives of Acoustics, 37, 1, 57-61.

2. Batko W., PAwlik P., StęPień B. (2015), Non-classical statistical methods in the uncertainty evaluation in acoustic research and modelling [in Polish: Nieklasyczne metody statystyczne $w$ ocenie niepewności $w$ badaniach $i$ modelowaniu akustycznym], Wydawnictwo Naukowe Instytutu Technologii Eksploatacji - PIB, Radom.

3. ISO/IEC Guide 98-3:2008, Uncertainty of measurement - Part 3: Guide to the expression of uncertainty in measurement (GUM:1995).

4. ISO/IEC Guide 98-3-SP1:2008, Supplement 1 - Uncertainty of measurement - Part 3: Guide to the expression of uncertainty in measurement (GUM:1995) - Propagation of distributions using a Monte Carlo method.

5. JAKUBIEC J. (2002), Application of Reductive Interval Arithmetic to Uncertainty Evaluation of Measurument Data Processing Algorithms [in Polish: Redukcyjna arytmetyka interwatowa $w$ zastosowaniu do wyznaczania niepewności algorytmów przetwarzania danych pomiarowych], Silesian University of Technology Press, Gliwice.

6. Moore R.E. (1962), Interval Arithmetic and Automatic Error Analysis in Digital Computing, Stanford, CA, PhD thesis, Stanford University.

7. Moore R.E. (1966), Interval Analysis, Englewood Cliffs NJ, Prentice-Hall.

8. PN-EN 1793-1:2013-05 - Road traffic noise reducing devices. Test method for determining the acoustic performance. Intrinsic characteristics of sound absorption.

9. PN-EN 1793-3:2001 - Road traffic noise reducing devices. Test method for determining the acoustic performance. Normalized traffic noise spectrum.

10. PN-EN ISO 354:2005 - Acoustics - Measurement of sound absorption in a reverberation room.

11. Przysucha B., Batko W., Szeląg A. (2015), Analysis of the accuracy of uncertainty noise measurement, Archives of Acoustics, 40, 2, 183-189.

12. StęPIEŃ B. (2016), Bootstrap Confidence Intervals for Noise Indicators, Acta Acustica United With Acustica, 102, 389-397.

13. Warmus M. (1956), Calculus of approximations, Bulletin de l'Academie Polonaise des Sciences, 4, 5, 253257.

14. WszoŁeK G. (2014), Uncertainty Analysis for Determination of Sound Absorption Evaluation Index $D L \alpha$, 7th Forum Acusticum 2014, Kraków. 